\title{
Fe-doped carbon aerogels from sodium alginate for the removal of methylene blue
}

\author{
Zuozhao Zhai ${ }^{1,2}$, Bin Ren ${ }^{1,2}$, Lihui Zhang ${ }^{1,2}$, Zhenfa Liu ${ }^{1,2, *}$ \\ ${ }^{1}$ Institute of Energy Resources, Hebei Academy of Sciences, Shijiazhuang 050081, China \\ ${ }^{2}$ Hebei Engineering Research Center for Water Saving in Industry, Shijiazhuang 050081, China
}

\begin{abstract}
In this article, Fe-doped carbon aerogels from sodium alginate were used for the removal of methylene blue (MB) in water. Under acidic condition, the sample carbonized at $700{ }^{\circ} \mathrm{C}(\mathrm{T} 700)$ undergoes $\mathrm{Fe}-\mathrm{C}$ micro-electrolysis to produce highly chemically active $\mathrm{Fe}^{2+}$ and $[\mathrm{H}]$ to degrade $\mathrm{MB}$. Under neutral or alkaline conditions, $\mathrm{Fe}^{2+}$ produced by $\mathrm{Fe}-\mathrm{C}$ micro-electrolysis become $\mathrm{Fe}(\mathrm{OH})_{3}$, which can effectively adsorb MB. In addition, when $\mathrm{T} 700$ combines with $\mathrm{H}_{2} \mathrm{O}_{2}$ to form Fenton system, the MB removal efficiency was significantly improved. The Fe-doped carbon aerogels can be used in wastewater treatment and when combine the materials with $\mathrm{H}_{2} \mathrm{O}_{2}$ can greatly improve the $\mathrm{MB}$ removal efficiency.
\end{abstract}

\section{Introduction}

MB is a commonly used dye which is widely used in industrial and medical fields. However, the extensive application of MB produced a large amount of industrial wastewater. High concentrations of MB can poison or even die animals. Therefore, MB treatment is one of the current research focuses in the field of wastewater treatment. MB treatment includes biological $[1,2]$, physical $[3,4]$ and chemical $[5,6]$ methods. Chemical method includes chemical oxidation, electro-oxidation, photo-oxidation, and ultrasonic oxidation, etc., which is a hot research for MB wastewater treatment.

$\mathrm{Fe}-\mathrm{C}$ micro-electrolysis is an economical and environmentally friendly wastewater treatment technology, which is widely used in the treatment of highconcentration organic wastewater [7-10]. When iron filings and carbon particles are immersed in acidic wastewater, numerous micro-galvanic cells are formed in the wastewater due to the electrode potential difference between iron and carbon $(1.2 \mathrm{~V})$. Low-potential iron becomes the anode, and high-potential carbon becomes the cathode. The electrochemical reaction under acidic conditions occurs as follows:

Anodic oxidation: $\mathrm{Fe}-2 \mathrm{e}^{-} \rightarrow \mathrm{Fe}^{2+}$

Cathodic reduction: $2 \mathrm{H}^{+}+2 \mathrm{e}^{-} \rightarrow 2[\mathrm{H}] \rightarrow \mathrm{H}_{2}$ (2)

The $\mathrm{Fe}^{2+}$ and $[\mathrm{H}]$ produced by the reaction have high chemical activity can change the structure of organic substances in wastewater. However, the reaction time of $\mathrm{Fe}-\mathrm{C}$ micro-electrolysis is long. Fenton reaction is a simple and efficient wastewater treatment technology [1113]. This process is based on the reaction of $\mathrm{H}_{2} \mathrm{O}_{2}$ and $\mathrm{Fe}^{2+}$ to produce highly oxidizing hydroxyl radicals $(\cdot \mathrm{OH})$ to degrade organics in wastewater.
The reaction mechanism is as follows:

$$
\begin{gathered}
\mathrm{H}_{2} \mathrm{O}_{2}+\mathrm{Fe}^{2+} \rightarrow \mathrm{Fe}^{3+}+\mathrm{OH}^{-}+\mathrm{HO} \bullet \\
\mathrm{H}_{2} \mathrm{O}_{2}+\mathrm{Fe}^{3+} \rightarrow \mathrm{Fe}^{2+}+\mathrm{H}^{+}+\mathrm{HO}_{2} \bullet \\
\mathrm{H}_{2} \mathrm{O}_{2}+\mathrm{HO}_{2} \bullet \rightarrow \mathrm{H}_{2} \mathrm{O}+\mathrm{O}_{2}+\mathrm{HO} \bullet \\
\mathrm{HO} \bullet+\mathrm{RH} \rightarrow \mathrm{R} \bullet+\mathrm{H}_{2} \mathrm{O} \\
\mathrm{R} \bullet+\mathrm{Fe}^{3+} \rightarrow \mathrm{Fe}^{2+}+\mathrm{R}^{+} \\
\mathrm{R}^{+}+\mathrm{O}_{2} \rightarrow \mathrm{ROO}^{+} \rightarrow \mathrm{CO}_{2}+\mathrm{H}_{2} \mathrm{O}
\end{gathered}
$$

Therefore, the combine of Fe-C micro-electrolysis and Fenton reaction will effectively improve their respective problems.

In this paper, The Fe-doped carbon aerogels were employed to treat MB in wastewater. The materials have broad application prospects in the field of wastewater treatment because they use environmentally friendly sodium alginate as raw material, the preparation process is simple, and the MB removal efficiency in wastewater is high.

\section{Materials}

Sodium alginate, $\mathrm{Fe}\left(\mathrm{NO}_{3}\right)_{3}$, was purchased from Aldrich Co. MB was purchased from Damao Chemical Reagent Factory. $\mathrm{H}_{2} \mathrm{SO}_{4}$ and $\mathrm{NaOH}$ were purchased from Tianjin Fengchuan Chemical Reagent Technologies Co., Ltd.

\subsection{Materials preparation}

Fe-doped carbon aerogels were synthesized as followings: sodium alginate was dissolved in $\mathrm{H}_{2} \mathrm{O}$ (solution $\mathrm{A}$ ) and $\mathrm{Fe}\left(\mathrm{NO}_{3}\right)_{3}$ was dissolved $\mathrm{H}_{2} \mathrm{O}$ (solution $\mathrm{B}$ ). Solution $\mathrm{A}$ and solution $\mathrm{B}$ were mixed to obtain sodium alginate hydrogels. The hydrogels were placed in a freeze dryer

\footnotetext{
$\overline{{ }^{*} \text { Corresponding author: lzf63@sohu.com }}$
} 
obtain aerogels. Then the aerogels were transferred in a carbonization furnace at $500,600,700,800$, and $900{ }^{\circ} \mathrm{C}$ (the corresponding sample is named as T500, T600, T700, T800, and T900, respectively).

\subsection{Characterization}

The XRD patterns of the carbon aerogels were monitored by an Ultima X-ray diffractometer under copper $\mathrm{K} \alpha$ radiation at $40 \mathrm{kV}$ and $40 \mathrm{~mA}$. A TU-1900 UV-vis spectrometer was used to measure the concentration of $\mathrm{MB}$ at $665 \mathrm{~nm}$. The total iron content was measured using the TU-1900 UV-vis spectrometer at $510 \mathrm{~nm}$ according to iron-phenanthroline spectrophotometry.

\subsection{Removal experiments}

In the $\mathrm{Fe}-\mathrm{C}$ micro-electrolysis experiments, $50 \mathrm{mg} \mathrm{Fe}-$ doped carbon aerogels were added to $50 \mathrm{ml} \mathrm{MB}$ aqueous solution $\left(50 \mathrm{mg} \mathrm{L}^{-1}\right)$ at $25^{\circ} \mathrm{C}, \mathrm{pH}=2.5$. The $\mathrm{pH}$ was selected as the variable operating parameter to investigate the removal efficiency of $\mathrm{MB}$. The $\mathrm{pH}$ was adjusted by $\mathrm{H}_{2} \mathrm{SO}_{4}$ and $\mathrm{NaOH}$. The $\mathrm{MB}$ removal efficiency was calculated using the following equation:

$$
D(\%)=\left(C_{0}-C_{t}\right) / C_{0} \times 100
$$

where $\mathrm{C}_{0}$ is the initial $\mathrm{MB}$ concentration $\left(\mathrm{mg} \mathrm{L}^{-1}\right)$ and $\mathrm{C}_{\mathrm{t}}$ is the $\mathrm{MB}$ concentration at time $\mathrm{t}\left(\mathrm{mg} \mathrm{L}^{-1}\right)$.

In the Fenton experiments, $12 \mathrm{mg} \mathrm{T700} \mathrm{was} \mathrm{added} \mathrm{to}$ $40 \mathrm{ml} \mathrm{MB}$ aqueous solution $\left(50 \mathrm{mg} \mathrm{L}^{-1}\right)$ with $\mathrm{H}_{2} \mathrm{O}_{2}$ was added at $25^{\circ} \mathrm{C}, \mathrm{pH}=2.5$.

\section{Result and Discussion}

The MB removal efficiency of Fe-doped carbon aerogel samples are shown in Fig 1 . After $9 \mathrm{~h}$, the MB removal efficiency of T500, T600, T700, T800 and T900 is 20.1\%, $25.4 \%, 96.0 \%, 94.7 \%$ and $93.0 \%$, respectively. It can be seen that the MB removal efficiency of T500 and T600 is significantly lower than other samples. And the MB removal efficiency of samples T700, T800 and T900 are higher than $92 \%$ after $9 \mathrm{~h}$. In addition, T700 has the best MB removal efficiency that can reach $96.0 \%$ after $9 \mathrm{~h}$.

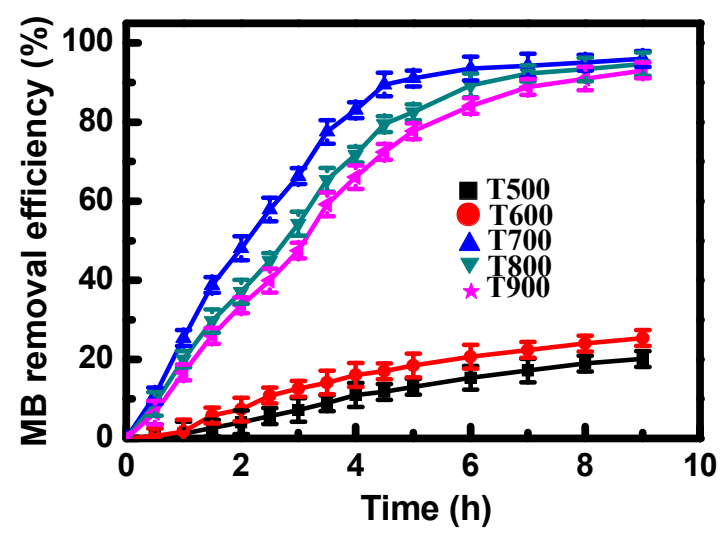

Figure 1. The MB Removal efficiency of Fe-doped carbon aerogels.
PH has a significant effect on Fe-C micro-electrolysis, so $\mathrm{pH}$ was selected as the operating parameter to investigate the MB removal efficiency of T700. As shown in Fig. 2, T700 has substantial MB removal efficiency under different $\mathrm{pH}$ conditions. This may be due to under acidic conditions, T700 produces highly chemically active $\mathrm{Fe}^{2+}$ and $[\mathrm{H}]$ by $\mathrm{Fe}-\mathrm{C}$ micro-electrolysis. $\mathrm{Fe}^{2+}$ and $[\mathrm{H}]$ have strong oxidizing properties which can destroy the molecular structure of MB. And the stronger the acidity, the better the MB removal efficiency of T700. Under neutral or alkaline conditions, precipitation occurs in the MB solution as shown in the illustration in Fig. 2. And as the $\mathrm{pH}$ increases, the amount of precipitation increases. It is due to that $\mathrm{Fe}^{2+} / \mathrm{Fe}^{3+}$ formed by iron-carbon micro-electrolysis react with $\mathrm{OH}^{-}$in the solution to form $\mathrm{Fe}(\mathrm{OH})_{2} / \mathrm{Fe}(\mathrm{OH})_{3}$ precipitate. MB can form monovalent cationic quaternary ammonium groups in solution, while the $\mathrm{Fe}(\mathrm{OH})_{3}$ colloid is negatively charged, so the material can effectively adsorb MB under neutral or alkaline conditions.

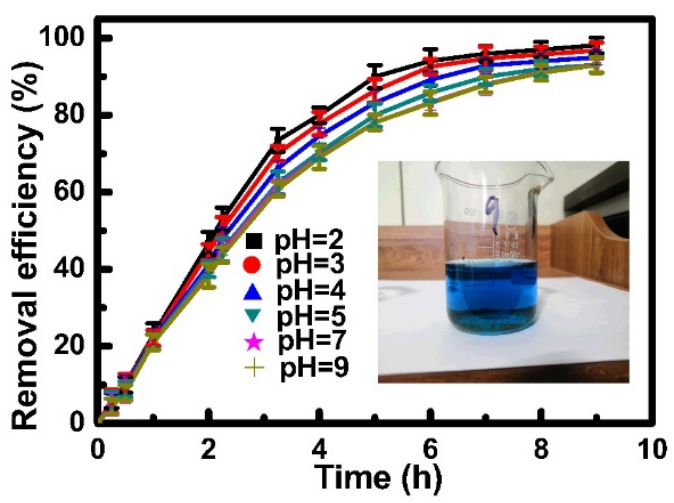

Figure 2. The $\mathrm{pH}$ effect on MB removal efficiency of $\mathrm{T} 700$.

In order to confirm that the removal of $\mathrm{MB}$ by the sample is mainly caused by Fe-C micro-electrolysis, T700 was washed by $\mathrm{HCl}$ (named as $\mathrm{T} 700-\mathrm{H}$ ). Fig. 3a shows the XRD pattern of T700-H. It can be seen that the peaks of $\mathrm{Fe}$ in the sample have disappeared, and only the peak of graphitic carbon remains. Fig. $3 \mathrm{~b}$ shows the MB removal efficiency of $\mathrm{T} 700$ and $\mathrm{T} 700-\mathrm{H}$. The MB removal efficiency of $\mathrm{T} 700-\mathrm{H}$ is only $4.1 \%$ while the MB removal efficiency of T700 is $96.0 \%$ after $9 \mathrm{~h}$. It can be concluded that the removal of MB by T700 is mainly caused by FeCmicro-electrolysis.

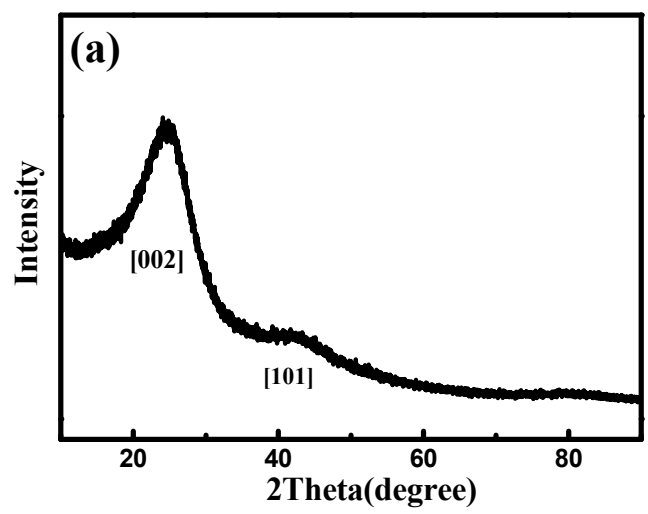




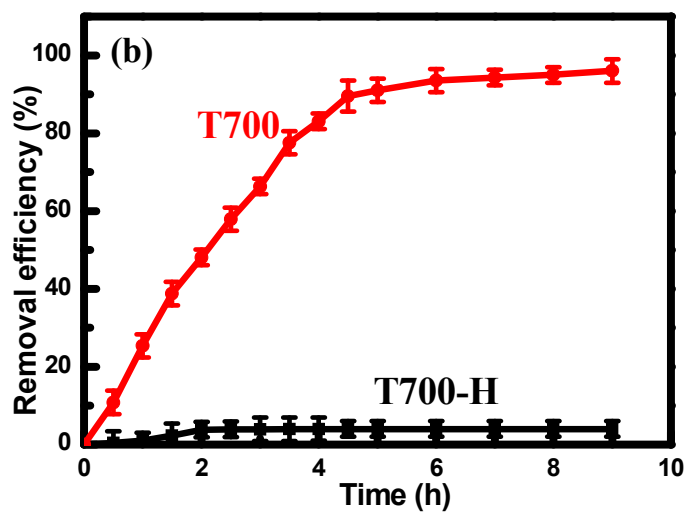

Figure 3. (a) XRD pattern of $\mathrm{T} 700-\mathrm{H}$ and (b) the $\mathrm{MB}$ removal efficiency of $\mathrm{T} 700$ and $\mathrm{T} 700-\mathrm{H}$.

$\mathrm{Fe}^{2+}$ produced by $\mathrm{Fe}-\mathrm{C}$ micro-electrolysis can form a Fenton system with $\mathrm{H}_{2} \mathrm{O}_{2}$ to improve the $\mathrm{MB}$ removal efficiency. In order to confirm the efficient removal efficiency of the Fenton system, a comparative experiment was performed. Fig. 4 shows the result of the comparative experiment. It can be seen that the MB removal efficiency of $\mathrm{T} 700+\mathrm{H}_{2} \mathrm{O}_{2}$ can reach $99.7 \%$ after $3 \mathrm{~h}$ while the MB removal efficiency of T700 and bare $\mathrm{H}_{2} \mathrm{O}_{2}$ are $66.3 \%$ and $6.3 \%$, respectively. It can be concluded that adding $\mathrm{H}_{2} \mathrm{O}_{2}$ to $\mathrm{T} 700$ can effectively improve $\mathrm{MB}$ removal efficiency.

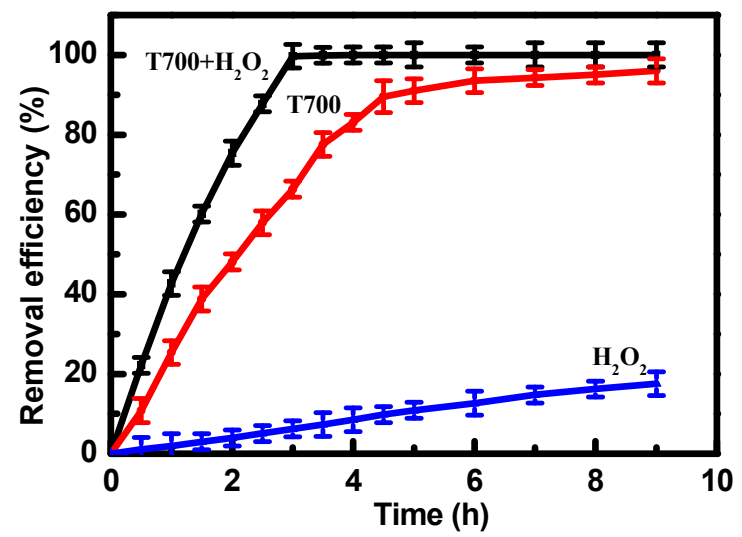

Figure 4. The $\mathrm{MB}$ removal efficiency of $\mathrm{T} 700+\mathrm{H}_{2} \mathrm{O}_{2}, \mathrm{~T} 700$ and $\mathrm{H}_{2} \mathrm{O}_{2}$.

The addition time of $\mathrm{H}_{2} \mathrm{O}_{2}$ is a key factor affecting the Fenton reaction. Figure $5 \mathrm{a}$ shows the time required for sample T700 to remove more than $99 \%$ MB by adding 0.5 $\mathrm{ml} \mathrm{H}_{2} \mathrm{O}_{2}$ after $\mathrm{Fe}-\mathrm{C}$ micro-electrolysis at different times. Figure $5 \mathrm{a}$ shows that the longer the time of the $\mathrm{Fe}-\mathrm{C}$ micro-electrolysis reaction, the higher $\mathrm{MB}$ removal effeciency after adding $\mathrm{H}_{2} \mathrm{O}_{2}$. The removal rate of $\mathrm{MB}$ reached $99 \%$ in 180 min when $\mathrm{H}_{2} \mathrm{O}_{2}$ and $\mathrm{T} 700$ were added at the same time, but reached $99 \%$ in only 3 min when $\mathrm{H}_{2} \mathrm{O}_{2}$ was added after 2 hours of $\mathrm{T} 700$ added. This result may be because the concentration of $\mathrm{Fe}^{2+}$ produced by $\mathrm{Fe}$ $\mathrm{C}$ micro-electrolysis gradually increases with time, which promotes the Fenton reaction and improves the MB removal efficiency. To further prove this speculation, the concentration of $\mathrm{Fe}^{2+}$ in solution was determined at different times during $\mathrm{Fe}-\mathrm{C}$ micro-electrolysis. Figure $5 \mathrm{~b}$ shows that the concentration of $\mathrm{Fe}^{2+}$ in the solution increases with increasing $\mathrm{Fe}-\mathrm{C}$ micro-electrolysis time. With increased $\mathrm{Fe}-\mathrm{C}$ micro-electrolysis time, the $\mathrm{MB}$ removal effeciency is better after adding $\mathrm{H}_{2} \mathrm{O}_{2}$. But adding $\mathrm{H}_{2} \mathrm{O}_{2}$ after 0.5 hours of $\mathrm{T} 700$ added shows the shortest total time of MB removal to $99 \%$.
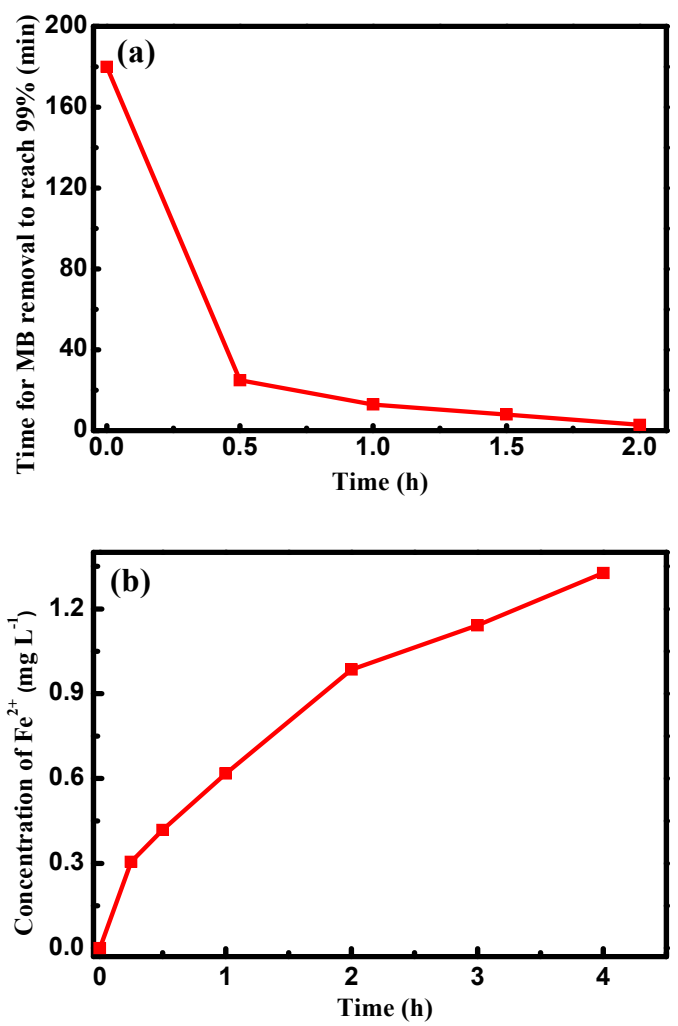

Figure 5. (a) The time of $\mathrm{H} 2 \mathrm{O} 2$ added after $\mathrm{T} 700$ added and (b) the concentration of $\mathrm{Fe} 2+$ produced by $\mathrm{Fe}-\mathrm{C}$ micro-electrolysis.

The amount of $\mathrm{H}_{2} \mathrm{O}_{2}$ added is an important factor affecting the Fenton reaction. Therefore, the experiment that investigated the effect of adding different amounts of $\mathrm{H}_{2} \mathrm{O}_{2}$ on the MB removal efficiency after 0.5 hours of $\mathrm{Fe}-$ $\mathrm{C}$ micro-electrolysis was applied. As shown in Figure 6, with increased $\mathrm{H}_{2} \mathrm{O}_{2}$, the $\mathrm{MB}$ removal efficiency is increase. But the $\mathrm{MB}$ removal efficiency is decreased when the amount of $\mathrm{H}_{2} \mathrm{O}_{2}$ is more than $0.4 \mathrm{ml}$. This difference may be because when the initial concentration of $\mathrm{H}_{2} \mathrm{O}_{2}$ is low, increasing the amount of $\mathrm{H}_{2} \mathrm{O}_{2}$ can effectively promote the Fenton reaction. However, when the concentration of $\mathrm{H}_{2} \mathrm{O}_{2}$ is too high, the hydrogen peroxide will be invalid decomposed, which will inhibit the progress of the Fenton reaction. The Fenton reaction can efficiently degrade organic pollutants in wastewater due to the strong oxidation ability of $\bullet \mathrm{OH}$. To determine the important role played by $\bullet \mathrm{OH}$, a set of comparative experiments were conducted. After 0.5 hours of Fe-C micro-electrolysis, $\mathrm{H}_{2} \mathrm{O}_{2}$ was directly added to sample 1, and two drops of isopropanol (a hydroxyl radical quencher) were added to sample 2 , followed by $\mathrm{H}_{2} \mathrm{O}_{2}$ added. The MB solution in sample 1 changed from blue to colourless in $7 \mathrm{~min}$, and the MB solution in sample 2 did not change significantly even after $2 \mathrm{~h}$. The comparative experimental results show that $\bullet \mathrm{OH}$ plays an important role in the MB removal. 


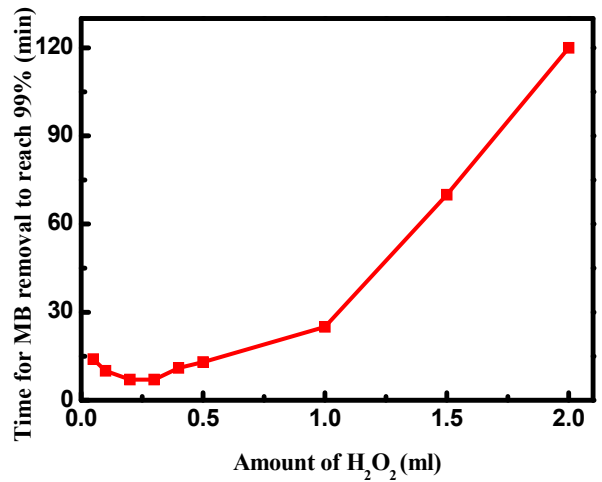

Figure 6. Effect of the amount of $\mathrm{H}_{2} \mathrm{O}_{2}$ on $\mathrm{MB}$ removal efficiency.

$\mathrm{PH}$ of the solution is another important factor affecting Fenton reaction. Figure 7 shows the effect of $\mathrm{pH}$ on the $\mathrm{MB}$ removal efficiency that adding $\mathrm{H}_{2} \mathrm{O}_{2}$ after 0.5 hours of T700 added. It can be seen that the MB removal efficiency can reach $99 \%$ only in $6 \mathrm{~min}$ at $\mathrm{pH}=2$. When the $\mathrm{pH}$ of the solution is greater than 4 , the $\mathrm{MB}$ removal efficiency is much lower than $99 \%$ after $120 \mathrm{~min}$. This is because $\mathrm{Fe}^{3+}$ can generate $\mathrm{Fe}(\mathrm{OH})_{3}$ precipitation at $\mathrm{pH}=$ 3.7 that leads to a decrease of $\mathrm{Fe}^{3+}$ content in the solution. Thus $\mathrm{Fe}^{3+}$ cannot be converted to $\mathrm{Fe}^{2+}$, resulting in a sharp decrease of $\mathrm{Fe}^{2+}$ in the solution, thereby inhibiting the Fenton reaction.

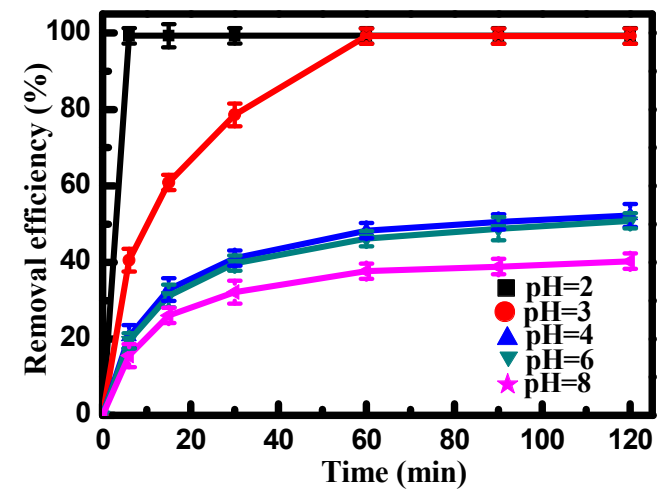

Figure 7. Effect of $\mathrm{pH}$ on $\mathrm{MB}$ removal efficiency.

\section{Conclusions}

In summary, The Fe-doped carbon aerogel were used for the MB removal in wastewater. The MB removal efficiency of $\mathrm{T} 700$ could reach $96.0 \%$ after $9 \mathrm{~h}$. T700 was selected for further research considering the energy consumption and the MB removal efficiency. Furthermore, the materials have good MB removal efficiency at different $\mathrm{pH}$. T700 was also used in combination with $\mathrm{H}_{2} \mathrm{O}_{2}$. The $\mathrm{MB}$ removal efficiency can reach to $99 \%$ in 3 min under the conditions that $\mathrm{pH}=2$ and $0.2 \mathrm{ml} \mathrm{H}_{2} \mathrm{O}_{2}$ was added after $0.5 \mathrm{~h}$ of $\mathrm{Fe}-\mathrm{C}$ micro-electrolysis reaction, These novel Fe-doped carbon aerogels will have broad application prospects in the field of wastewater treatment due to the environmentally friendly raw material, simple preparation process, and efficient removal of organics in wastewater.

\section{References}

1. R. Chen, Y. Zhang, L. Shen, X. Wang, J. Chen, A. Ma, W. Jiang, Chem. Eng. J. 268, 348-355 (2015).

2. M.C. Ncibi, B. Mahjoub, M. Seffen, J. Hazard. Mater. 139, 280-285 (2007).

3. R. Bin, Y. Xu, L. Zhang, Z. Liu, J. Taiwan Inst. Chem. E. 88, 114-120 (2018).

4. K. Samar, Theydan, J. Muthanna, Ahmed, J. Anal. Appl. Pyrol. 97, 116-122 (2012).

5. P. M. K. Reddy, P. Verma, C. J. Taiwan Inst. Chem. E. 58, 500-508 (2016).

6. M. Masrollahzadeh, M. Atarod, B. Jaleh, M. Gandomirouzbahani, Ceram. Int. 42, 8587-8596 (2016).

7. Z. Yang, Y. Ma, Y. Liu, Q. Li, Z. Zhou, Z. Ren, Chem. Eng. J. 315, 403-414 (2017).

8. X. Dou, R. Li, B. Zhao, W. Liang, J. Hazard. Mater. 182, 108-114 (2010).

9. Z. Ma, Y. Yang, Y. Jiang, B. Xi, T. Yang, X. Peng, X. Lian, K. Yan, H. Liu, Chem. Eng. J. 311, 183-190 (2017).

10. L. Zhang, Q. Yue, K. Yang, P. Zhao, B. Gao, J. Hazard. Mater. 342, 705-714 (2018).

11. L. Gu, N. Zhu, H. Guo, S. Huang, Z. Lou, H. Yuan, J. Hazard. Mater. 246-247, 145-153 (2013).

12. C. Zhang, M. Zhou, X. Yu, L. Ma, F. Yu, 160, 254262 (2015).

13. B. Hou, H. Han, S. Jia, H. Zhuang, P. Xu, K. Li, J. Taiwan Inst. Chem. E. 60, 352-360 (2015). 